Christopher Hart

University of Hertfordshire

\title{
Force-Interactive Patterns in Immigration Discourse: A Cognitive Linguistic Approach to CDA
}

\author{
To Appear in Discourse \& Society 22 (3)
}

\begin{abstract}
In the last few years a highly productive space has been created for Cognitive Linguistics inside Critical Discourse Analysis. So far, however, this space has been reserved almost exclusively for critical metaphor studies where Lakoff and Johnson's (1980) Conceptual Metaphor Theory has provided the lens through which otherwise naturalised or opaque ideological patterns in text and conceptualisation can be detected. Yet Cognitive Linguistics consists of much more than Conceptual Metaphor Theory. Its efficacy for Critical Discourse Analysis (CDA) may therefore extend beyond critical metaphor studies. In this paper, I propose that Talmy's $(1988,2000)$ theory of force-dynamics in particular represents a further, useful framework for the Cognitive Linguistic Approach to CDA. Using this analytical framework, then, I identify some of the indicators of, and demonstrate the ideological qualities of, force-dynamic conceptualisations in immigration discourse.
\end{abstract}

Keywords: critical discourse analysis, cognitive linguistics, force-dynamics, immigration discourse

\section{Introduction}

Cognitive Linguistics has recently gained significant ground in Critical Discourse Analysis (see Hart and Lukeš 2007; Hart in press b). Indeed, a dedicated Cognitive Linguistic Approach, which has largely found its niche in Critical Metaphor Analysis, can now be identified (e.g. Charteris-Black 2004; Koller 2004; Musolff 2004). The key claim of Critical Metaphor Analysis is that metaphorical expressions in text reflect and effect underlying construal operations which are ideological in nature. However, metaphor is just one kind of construal operation identified in Cognitive Linguistics (see Croft and Cruse 2004). Several others may also be ideologically significant and contribute to the realisation of discursive strategies of the kind identified in CDA (see Hart in press a). In this paper I analyse the role that one construal system, force-dynamics, plays in anti-immigration discourse. In Section 2, I introduce the Cognitive Linguistic Approach and present a typology of relevant construal systems. In Section 3, I introduce the theory of force-dynamics and show how it can be applied to uncover expressions of force. And in Section 4 I describe the various force-dynamic schemas which seem to underlie many representations in discourse on immigration. ${ }^{1}$ Finally, I conclude with some summary remarks in Section 5. 


\section{The Cognitive Linguistic Approach to CDA}

Within Fairclough's (1995) tripartite model of discourse and discourse analysis, it is description-stage analysis which has received most attention. Here, Halliday's Systemic Functional Linguistics has provided the methodology for ideological research in text analysis. Insufficient attention, however, has been paid to interpretation-stage analysis. As Fowler (1996: 7) puts it, 'the reader simply is not theorised'. In particular, according to O'Halloran (2003: 14), 'much of CDA suffers from a paucity of appreciation of language cognition'. This gap in the research is striking since the successful communication of ideology depends on cognitive processes reproduced in the minds of textconsumers. $^{2}$ Ideological discursive strategies of the kind identified in CDA (e.g. Reisigl and Wodak 2001) can only be brought into effect when the structures realising them receive cognitive representation. It is curious, then, that Cognitive Linguistics, which developed at around the same time as Critical Linguistics and explicitly addresses the relation between structures in language and cognition, has not until recently been a major framework called upon in critical discourse research. ${ }^{3}$

Whilst van Dijk adopts a cognitive perspective in CDA (e.g. 2001, 2002), Cognitive Linguistics is not a feature of his approach. Cognitive Linguistics is a specific school associated with Lakoff, Langacker, Talmy, Taylor, Fillmore and Fauconnier for example. It is not a single discipline but a paradigm of cognitive science and linguistics which comprises a number of research programmes related by a common set of assumptions. These assumptions include, for example, that grammar and semantics are both based on the same general processes as other domains of cognition, that linguistic knowledge is conceptual in nature and cannot be separated from non-linguistic knowledge, that meaning is based in experience, and that language serves to construe experience. ${ }^{4}$ Although Cognitive Linguistics sees no fundamental distinction between grammar and semantics, then, research still falls at two loci: Cognitive Grammar and Cognitive Lexical Semantics. Programmes of research across these two areas include Conceptual Metaphor Theory (Lakoff and Johnson 1980), Frame Semantics (Fillmore 1982), Mental Spaces (Fauconnier 1994), Cognitive Grammar (Langacker 1987, 1991) and Force-Dynamics (Talmy 1988).

The Cognitive Linguistic Approach to CDA can be characterised as investigating ideological patterns in text and conceptualisation. The so far fruitful synergy between Cognitive Linguistics and CDA has largely been confined to critical metaphor studies with Conceptual Metaphor Theory providing the theoretical framework. However, Cognitive Linguistics in CDA may extend beyond Critical Metaphor Analysis to create a broader but coherent Cognitive Linguistic Approach which incorporates aspects of Cognitive Grammar, Mental Spaces, Frame Semantics and Force-Dynamics (see Hart 2010).

Cognitive Linguistics is primarily concerned with conceptualisation - a dynamic, online cognitive process through which meaning is constructed. Unlike Functional Linguistics which is "speaker oriented" and "process-focussed", Cognitive Linguistics is "hearer-oriented" and "pattern-focussed". As such, it is well placed to address interpretation-stage analysis in CDA. Cognitive Linguistics can model ideological mental representations that text-consumers are prompted to construct in response to particular structures in text and which constitute their experience of the phenomena described. Moreover, Cognitive Linguistics is concerned with the very same phenomena that are of interest in CDA. For example, Cognitive Linguistics addresses within language and cognition the structuring of basic categories such as space and time, situations and events, entities, actions and processes, motion and location, force and causation, and intention and volition (Fauconnier 2006). 
The key claim of Cognitive Linguistics for CDA is that the structuring of these categories always involves 'construal'. The notion of construal refers to the fact that the same phenomenon is potentially conceptualised in any number of different ways but that alternative language structures impose particular conceptualisations on the scene at hand (Langacker 1991). Linguistic structures in text therefore reflect the text-producer's own conception of reality (or at least one they wish to promote in order to effect ideological discursive strategies). The concept of construal in Cognitive Linguistics, then, is consistent with the relativism of CDA, according to which, representation in text is 'always representation from some ideological point of view, as managed through the inevitable structuring force of transitivity’ (Fowler 1991: 85).

For Cognitive Linguistics, the relevant structuring system is not transitivity but a number of 'construal systems' or 'operations', including metaphor and force-dynamics, which are responsible for conceptualisation (Croft and Cruse 2004). These concept structuring systems offer 'a range of alternative structural characterizations, among which a speaker chooses so as to convey a particular conceptualization of a scene' (Talmy 2000: 214). Construal operations, then, are indexed in text and invited in text-consumers to engender ideological cognitive representations realising discursive strategies.

Several typologies of construal systems have been proposed and different labels applied. For example, Langacker (1987) surveys a number of systems under the rubric of 'focal adjustments'. However, Langacker's classification includes only systems based on general cognitive processes of attention and perspective. His classification does not include the construal operations identified in Cognitive Lexical Semantics such as categorisation and metaphor, both of which rely on the general cognitive process of comparison. Neither does it include force-dynamics. Hart (in press a) therefore presents a typology of construal operations drawn from Croft and Cruse (2004) and shows how they serve to realise three types of discursive strategy which he calls 'identification', 'framing' and 'positioning. 5 This typology is reproduced in table 1 below.

Table 1. Construal operations and discursive strategies

Identification /


Identification strategies concern which social actors are represented (explicitly or implicitly), in which roles, and to what degree of salience or 'granularity'. For example, those construal operations based in attention can de-focus or de-individuate certain social actors. Identification strategies, then, include those that fall under the general rubric of 'mystification' in Critical Linguistics (Fowler et al. 1979; Kress and Hodge 1979). They also include what we can call 'scope of reference' as categorisation (including metonymic categorisation and scalar adjustments) can be used to identify a certain set of social actors whilst precluding others as the subject of a predication. Framing strategies concern how an entity, action, event, process or relation, through categorisation and metaphor, is attributed particular evaluative qualities or structural properties. Framing strategies therefore include negativeOther presentation (van Dijk 1997), often through metaphorical strategies such as militarisation, naturalisation or biologisation (Reisigl and Wodak 2001), as well as a strategy we can call 'structural configuration'. Identification and framing appear in the same box because wherever there is explicit identification the choice of referring expression necessarily frames the actor(s) in some particular way by evoking associated evaluative scripts. And because identifying participants in particular roles ascribes to them particular qualities or statuses. Positioning strategies can be deictic, epistemic or deontic and concern the positioning of social actors/events in relation to one another (deictic) and the positioning of propositions in relation to one's conception of reality (epistemic) or morality (deontic). ${ }^{6}$ Positioning strategies, then, include proximisation and legitimisation as outlined by Cap (2006) and Chilton (2004) respectively.

One major contribution of the Cognitive Linguistic Approach is to offer new perspectives on semantic and grammatical structures which are staple objects of analysis in CDA but whose real impact has recently been called into question (cf. Widdowson 2004). For example, Hart (in press a) shows that identification strategies like agent-deletion or agent-substitution, through profiling/backgrounding and metonymy, do carry some conceptual import at the interpretation-stage. These analyses therefore give credence to the claim in CDA that grammatical metaphor can keep responsible actors 'in the semantic background' (Reisigl and Wodak 2001: 58). Another major advantage of the Cognitive Linguistic Approach is that it reveals very subtle ideological features of text and conceptualisation not previously recognised in CDA and so can add to the inventory of linguistic/conceptual categories to be targeted. For example, metaphor has not been a typical object of analysis in mainstream CDA but has recently received significant attention from a Cognitive Linguistic perspective where it has been shown to be an important device in covertly ideological or persuasive communication (Chilton 2004; Charteris-Black 2004; Koller 2004; Musolff 2004). Force-dynamics, however, has not been addressed anywhere in CDA, including in the Cognitive Linguistic Approach.

In the following sections, I introduce the theory of force-dynamics and show how this concept structuring system operates ideologically in discourse on immigration. Examples are all taken from a corpus of newspaper articles on immigration and asylum published in the UK between 2000 and $2006 .^{7}$

\section{Force-Dynamics}

In relation to the typology in table 1, force-dynamics is based on a fourth general cognitive process, Gestalt psychology, and serves in the realisation of identification, framing and positioning strategies. Gestalt construal operations impose image-schematic representations on the entity, relation or event cognised in order to constitute our experience of its basic structural configuration (Croft and Cruse 2004: 63). Image-schemas are abstract, holistic knowledge structures which emerge as distillations 
from repeated patterns of experience in our earliest interactions/observations within basic domains like SPACE, GEOMETRY, ACTION and FORCE (Johnson 1987: 29). They come to form the foundations of our conceptual system and can be called upon in conceptualisation. Image schemas serve to both connect and demarcate phenomena so that we can construe the world, and crucially can reason about it, in terms of whole, discrete schematic constructs. Image schemas are not specific images, then, but idealised, schematic structures, which represent the bare essence of their instantiations. They include, for example, a DISTANCE/PROXIMITY schema, a CONTAINER schema, various ACTION-CHAIN schemas and a whole set of FORCE-DYNAMIC schemas. ${ }^{8}$

Force-dynamic schemas arise from experience of pressure and motion. Unlike other construal operations, which are grounded in the visual modality, the force-dynamic system is grounded in somesthesia and kinaesthesia. Experience of force is ubiquitous. For example, all causal interaction requires the exertion of force, either as we act upon other objects or as we are acted upon by other objects (Johnson 1987: 42). It is not surprising, therefore, that patterns in experiences of physical interaction should 'work their way up into our system of meaning' (ibid.).

Force-dynamic schemas come to play a structuring role in our conceptualisations of physical interactions but also, by metaphorical extension, social, psychological, political, legal and linguistic interactions. The force-dynamic system is a generalisation that operates over concepts of 'causing', 'letting', 'helping' and 'hindering' (Talmy 2000: 409). It concerns the way in which objects are conceived to interact with respect to the exertion of force, resistance to force, the overcoming of such resistance, barriers to the exertion of force and the removal of such barriers (Talmy 2000: 219). It ought to be apparent, then, that the force-dynamic system might function in discourse surrounding immigration. And indeed, as reflected in and reified by particular representations in text, the forcedynamic system does seem to be constitutive of conceptualisations of immigration; both of the physical process of migration itself but also legal and political processes like amnesty, application and appeal. Immigration issues, however, need not necessarily be construed in terms of force interactions. That is, the force-dynamic system need not be invoked in their conceptualisation. ${ }^{9}$ Any forcedynamic representation in discourse on immigration is therefore inherently ideological. To illustrate this consider the contrast between (1) and (2):

(1) The Mirror, 10 May 2002

It's estimated that between 1,000 and 1,200 asylum seekers are coming into the country every month.

(2) Sunday Telegraph, 28 July 2002

As asylum seekers continue to arrive in Britain at the rate of 1,500 a week, the number of camps may eventually rise to 20 .

In (1) immigration is construed as force-dynamically neutral. The process of migration is represented as one of straightforward motion. There is no hindrance to the motion and no causation behind it. Hence, there is only one participant, the grammatical subject 'between 1,000 and 1,200 asylum seekers', and no force interaction. By contrast, in (2) there is a second, implicit participant. The use of continue to suggests the presence either of some causative force compelling the subject participant to migrate to Britain or some barrier to the process of migration in spite of which asylum seekers are still able to arrive in Britain. The two different construals are made explicit in (3) and (4) respectively. In (3) desperation, conceived of as a psychological 'pressure', acts as a force compelling refugees to migrate to Britain. In (4) a raft of reforms presents a barrier to the process of immigration but asylum numbers nevertheless continue to increase. 
(3) The Express, 6 November 2002

Critics believe they [refugees] will continue to attempt the journey even now, because they are desperate to enter the UK.

(4) Daily Telegraph, 8 Oct. 2002

But after watching asylum numbers continue to rise despite a raft of reforms, Mr Blunkett yesterday resurrected the idea ...

There are various other adverbial 'indicators' or 'facilitators' of force-interactive conceptualisations. For example keep on in (5) and still in (6):

(5) Daily Mail, 11 November 2002

Calais crisis as asylum seekers keep on coming.

(6) Daily Mail, 1 March 2003

And from Calais, of course, they [asylum seekers] are still coming.

Force-interactive construals, then, are prompted by closed class elements like conjunctions (e.g. because, despite) which specify the role and relative strength of an opposing participant to the one encoded as subject and semi-closed class elements such as certain adverbials which indicate forcedynamic opposition in general (Talmy 2000: 416). ${ }^{10}$ Force-interactive construals are also expressed by open-class lexical elements, which, as a result, are brought into systematic relationships with one another inside an order of discourse. These 'force-dynamic indicators', then, when they appear in text, reflect the text-producer's construal of the scene as a force interaction and prompt for the textconsumer to conceptualise the scene in the same way, with various ideological consequences. They can therefore usefully add to the inventory of linguistic categories analysed in CDA.

In Talmy's (2000) terminology, the two participants or 'force-interacting entities' in force-dynamic construals are referred to as Agonist (Ago) and Antagonist (Ant). ${ }^{11}$ In the force-dynamics system, the Agonist is 'the entity whose circumstance is at issue' (Talmy 2000: 415). In (3) the Agonist is asylum seekers. Agonists have an 'intrinsic force tendency' toward action (including motion) or rest and are subject to force interactions of various kinds with the Antagonist. In (3) the Antagonist is a raft of reforms which acts upon the Agonist to hinder the process of immigration. ${ }^{12}$ Depending on the perceived relative strengths of Ant and Ago, the Agonist is represented as either realising its intrinsic force tendency or not in a 'resultant of force interaction'. Talmy uses the diagrammatic notation in Figure 1 to represent the various elements which make up the force-dynamic system. ${ }^{13}$

a. Force entities

Agonist (Ago):

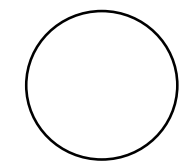

Antagonist (Ant):

\section{b. Intrinsic force tendency}

toward action:

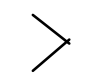

toward rest: 
c. Balance of strengths

stronger entity: +

weaker entity: -

\section{d. Resultant of force interaction}

action:

rest:

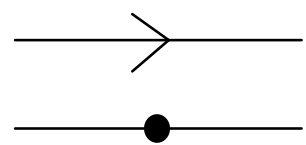

Figure 1. Elements of force-dynamics

This 'grammar' gives rise to various force-dynamic schemas which, alongside other idealised cognitive models, can be called upon to structure our conceptualisation of situations and events. Conceptualising immigration as a force interaction is in the first place ideological since, as demonstrated in the contrast between (1) and (2), a force-dynamic representation is only one available construal. The same material process can be represented either as a force interaction or as forcedynamically neutral. Imposing a force-interactive construal is further ideological because in doing so a set of 'entailments' are carried forward which can serve to realise particular discursive strategies. Entailments in this sense are defined as 'implications of the internal structure of image schemata' (Johnson 1987: 22). Image schemas are especially important ideologically, then, because they 'constrain and limit meaning as well as patterns of inference in our reasoning' (ibid. p. 42).

Recall that image schemas are holistic. They have an 'internal logic' which is imparted as a whole when they are apprehended to conceptualise a given scene. The structural configuration strategy of force-dynamics in immigration discourse entails that (i) immigration is framed as a physical, perhaps violent, interaction invoking a 'struggle' and (ii) that the actors encoded as Ant and Ago are positioned in opposition to one and other. Within the force-dynamics system there is then a further 'ideological dimension in the text-producer's decision as to which participant a role is assigned' (Wolf and Polzenhagen 2003: 265). Realising an identification strategy of role assignment, immigrants and asylum seekers are, of course, routinely cast in the role of Agonist. This has the consequent effect of framing immigrants and asylum seekers as instigators of force interactions.

We now turn to the force-interactive schemas invoked in anti-immigration discourse. Following Talmy (2000), force schemas can be organised into two categories: 'steady-state opposition' schemas and 'shift-in-state of opposition' schemas.

\section{Force-Interactive Patterns in Immigration Discourse}

\subsection{Steady-State Opposition Schemas}

The steady-state schemas are given in figure 2. The schemas in figure 2 constitute a natural set in so far as they involve an 'extended' force relation between Ant and Ago. Within the set, as Talmy points out, relations between pairs can be seen. For example, the patterns in a. and b. are of a 'despite' type in which the Ago realises its intrinsic force tendency in spite of some force enacted upon it: either by continuing to move (a.) or by continuing to stay in place (b.). In contrast, c. and d. are both of a 'causative' kind in which the Ago is unable to realise its intrinsic force tendency: either because it is caused to come to a halt (c.) or because it is caused to move (d.). 
a.

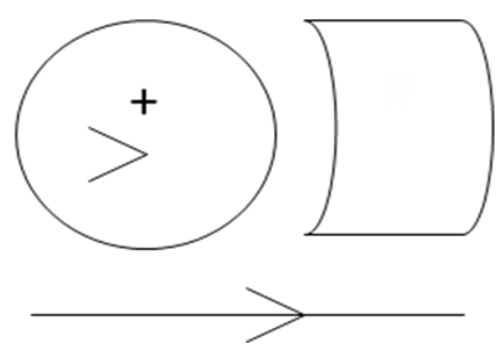

c.

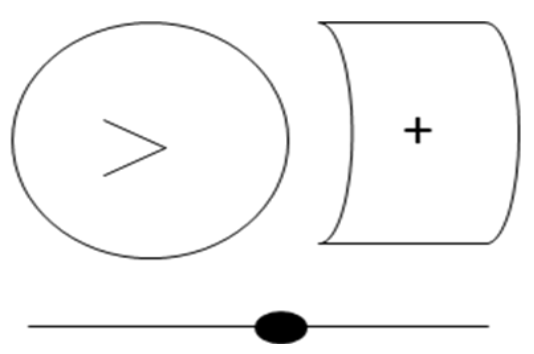

b.

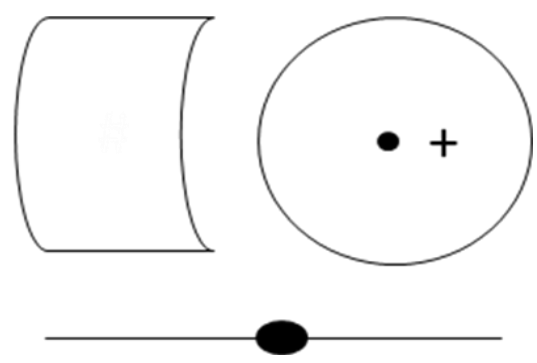

d.

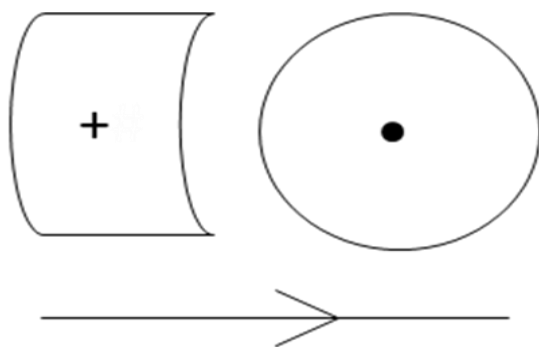

Figure 2. Steady-state opposition schemas

Perhaps the most ubiquitous schemas to be found in anti-immigration discourse are the 'despite' types modelled in figure $2 \mathrm{a}$. and $2 \mathrm{~b}$. The schema in $2 \mathrm{a}$., which arises from our experience of overcoming obstacles, is of a 'hindrance' relation between Ant and Ago. This is the schema invoked to conceptualise the scene in (4). However, consider two further examples:

(7) Daily Telegraph, 21 May 2000

Downing Street acknowledge that illegal immigration was an issue because of growing frustrations over [the stream of people ${ }_{A G O}$ ] getting into Britain from France through the Channel tunnel.

(8) Sunday Times, 4 September 2005

[Illegal immigrants ${ }_{\mathrm{AGO}}$ ] are getting into Britain by enrolling on university degrees, obtaining visas to stay for the length of their courses and then failing to turn up to study.

Although getting appears relatively neutral in comparison to more emotive verbs often analysed in the same construction, such as 'flooding' (Gabrielatos and Baker 2008), a force-dynamic analysis reveals the ideological properties of this verb. Getting implies the presence of some physical or legal barrier which the Ago is able to negotiate in order to realise its intrinsic force tendency. In (7) this is an implied physical barrier in the form of border control. In (8) this is an implied legal hurdle which immigrants overcome by exploiting some 'loop-hole' in the law. The construal encoded in (7) and (8) therefore also involves the force-dynamic schema given in Figure 2a. ${ }^{14}$ The Ago has an intrinsic force tendency toward action which is hindered by the Ant. However, the Ago is the stronger of the two entities and the resultant of force interaction is still action. The schema in Figure 2a. entails that immigration is construed as a process not currently under control and that immigrants are presented as persistent beings able to penetrate our 'protective' barriers thus realising a spatial deictic positioning 
strategy of proximisation. In proximisation (see Cap 2006) an entity construed as negative-Other is presented as 'closing in' on the entity, which includes the text-consumer, construed as positive-Self.

The 'despite' type in Figure 2b. is of a 'resistance' relation held between Ago and Ant. The Ago has an intrinsic tendency toward rest but is subject to a compelling force toward motion enacted upon it by the Ant. In this conceptualisation the Ago is again presented as the stronger of the two entities and therefore able to realise its intrinsic force tendency, this time toward rest. The Ago remains in place in spite of the force exerted upon it by the Ant. The representations in (9) and (10) both activate this schema.

(9) The Sun, 31 June 2001

[About 20,000 illegal immigrants ${ }_{\mathrm{AGO}}$ ] remain in Britain despite [a Government pledge to crack down on them $\left.{ }_{\mathrm{ANT}}\right]$.

(10) The Daily Telegraph, 1 February 2001

... it seems likely that [most ${ }_{\mathrm{AGO}}$ ] stay on indefinitely despite having been [told to go ${ }_{\mathrm{ANT}}$ ] - thus making a comprehensive mockery of the whole sorry business.

Verb choices remain and stay on in the main clause mark a force-interactive construal with the role of the Ant as the weaker entity expressed by the conjunction despite. The current location of the Ago is in spite of some force from an Ant attempting unsuccessfully to move (or remove) it. In both cases, the Ant is explicitly spelled out in the subordinate clause as the illocutionary force of a speech act. Imposing this schema on the scene entails that immigrants are conceptualised as stubborn, irremovable objects.

The schema in 2a. is counterposed by the schema in $2 \mathrm{c}$. which is constitutive of our concept of prevention and is thus clearly integral to anti-immigration discourse. In contrast to 2a., the schema in 2c. involves an Ant as the stronger of the two entities able to prevent the Ago from realising its intrinsic force tendency toward motion. The schema is invoked in examples such as (11) and (12).

(11) Sunday Mirror, 7 July 2002

The spokesman said [two GNIB members based in Amsterdam's Schiphol Airport for a month ${ }_{\text {ANT }}$ ] had resulted in ... [a significant number of illegal immigrants ${ }_{\mathrm{AGO}}$ ] being blocked.

(12) Mail on Sunday, 22 September 2002

[About 200 people $_{\text {AGO }}$ ] have been stopped by [French police ${ }_{\text {ANT }}$ ] at the Channel Tunnel in the past 18 months ...

The verbs block and stop indicate a physical force encounter between the two entities encoded as Ant and Ago. The semantics of the verbs specify the role of a stronger Ant which in both examples is made explicit. This is in contrast to get in (7) and (8), the semantics of which specifies the role of a weaker Ant. Crucially, though, in apprehending both schemas 2a. and 2c. immigrants are construed in a negative way as inherently forceful actors. Immigration is conceptualised in terms of a 'force vector' whose 'terminal point', where the impact of the force will be felt, unless otherwise abated, is Britain (the 'landmark' in Cognitive Grammar).

Conceptualisations of immigration based on the three schemas discussed so far fail to take into account the causes or motivations of migration. By not representing the causal nature of immigration the text-producer presents immigrants as the source of the force vector and ignores the motives for 
migration in the first place. There is therefore an ideological dimension in choosing whether or not to designate the antecedent in a chain of causal interaction.

The schema invoked in conceptualising the causes of immigration is the one depicted in $2 \mathrm{~d}$. This schema counterposes the one in Figure $2 b$. Like the schema in $2 b$., it involves an Ago with an intrinsic tendency toward rest. And the Ago is similarly subject to a compelling force enacted upon it by an Ant. However, the schema in $2 \mathrm{~d}$. captures an extended causative relation which is manifested in the fact that the Ago is unable to realise its intrinsic tendency and is instead compelled toward movement. The embodied basis of this schema lies in our experience of things (including ourselves) being driven or drawn by some external physical force.

As we have suggested, though, force-interactive construals are not restricted to the physical domain but extend to the intra-psychological domain incorporating drives and desires as metaphorical force interactions. Representations which recognise the causes compelling individuals toward migration can focus on either 'push' or 'pull' factors. ${ }^{15}$

Push factors include the desire to escape poverty or persecution. Representations which distinguish push factors tend to be more sympathetic toward the plight of immigrants and asylum seekers. Antiimmigration discourse more typically focuses on pull factors such as work or welfare which supposedly act as 'magnetic' forces on immigrants/asylum seekers. Consider (13) and (14) in which the force-interactive construal is indicated by drawn and lure and the role of the stronger Ant is indicated by because.

(13) Daily Mail, 21 May 2003

[Asylum seekers ${ }_{\mathrm{AGO}}$ ] are drawn to the UK because [it is so easy to work here illegally ${ }_{\mathrm{ANT}}$ ], the head of a Leftwing think-tank warned yesterday.

(14) Mail on Sunday, 25 March 2001

There have been claims that [the Romanians ${ }_{\mathrm{AGO}}$ ] had travelled to Britain again because of the lure of [free housing and benefits given to their-relatives in Britain ${ }_{\mathrm{ANT}}$ ].

The construal in (13) and (14) is of an Ago with an intrinsic tendency toward rest but which is acted upon by the stronger Ant whose compelling force the Ago is unable to resist and the resultant of force interaction is action. Note, then, that although the Ago is not construed as intrinsically forceful as in 2a. and 2c. its caused action is still construed in terms of a force vector with a trajectory toward Britain.

\subsection{Shift in State of Opposition Schemas}

In addition to the four steady-state schemas, there are four shift-in-state of opposition schemas invoked in anti-immigration discourse. These schemas capture changes in time to the condition of the Ant which effect a change in the force tendency of the Ago. In contrast to the steady-state schemas, shift-in-state of opposition schemas are dynamic and involve 'onset' causation or letting. The four shift-in-state of opposition schemas are represented in figure 3. Of these, e. and f. are of an onset 'letting' type where a stronger Ant previously in place leaves its state of impingement thus allowing the weaker Ago to realise its intrinsic tendency either toward action (e.) or rest (f.). The patterns in g. and $h$. are both of an onset 'causation' type in which a stronger Ant not previously in place comes into position against a weaker Ago to prevent it from realising its intrinsic tendency: either by causing it to move (g.) or by causing it to come to a halt (h.). 


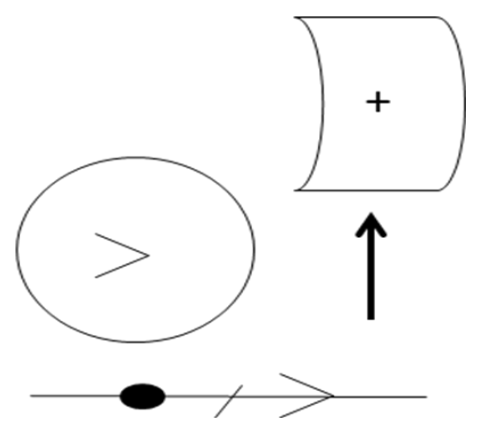

g.

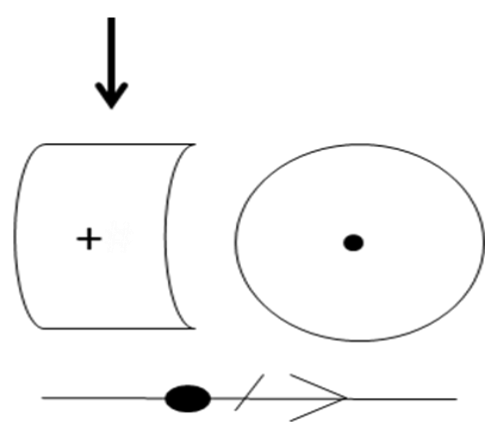

f.

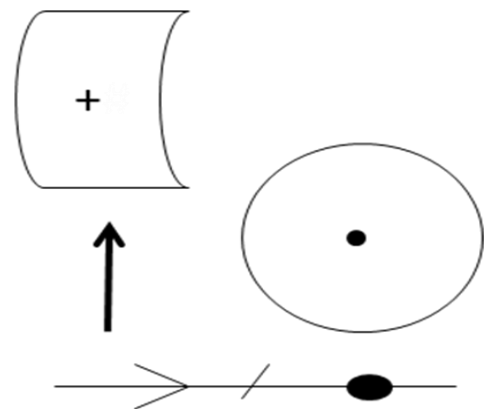

h.

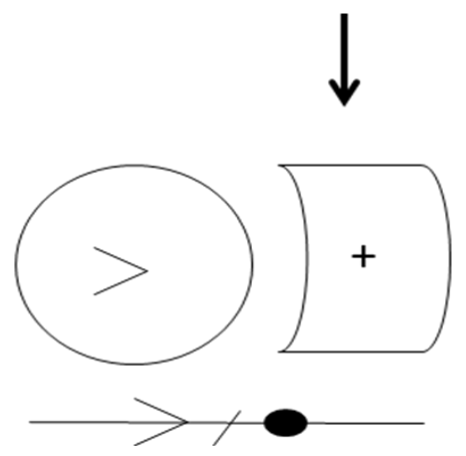

Figure 3. Shift-in-state of opposition schemas

Perhaps the most common shift-in-state of opposition schemas to be found in anti-immigration discourse are the ones depicted in e. and f., which underpin the concept of permission in general. The schema in e. constitutes the prototypical concept of permission, onset letting of motion, and is invoked in (15) and (16):

(15) The Express, 26 July 2001

Meanwhile, experts predict an appeal court ruling will let [hundreds more people ${ }_{\text {AGo }}$ ] into Britain

(16) Daily Mail, April 102003

The low- skilled migration programme, starting in May with a quota of 10,000 migrants each for the food processing and hospitality sectors, will allow [many who might otherwise try to come to the UK as asylum seekers ${ }_{\mathrm{AGO}}$ ] to enter legally with work permits.

In both examples, notice that the Ago now appears as the direct object of the relevant verb, the forcedynamic indicator, the semantics of which suggest the role of a stronger Ant previously in place preventing the Ago from realising its intrinsic tendency toward motion. However, the Ant disengages thereby releasing the Ago to manifest its tendency. In each example the Ant is left implicit. But it can be taken as a change in law brought about by precedent in (15) or policy in (16). The image invoked in these examples, then, is one in which a forceful entity previously kept in check is allowed through as the barrier is removed. Such a conceptualisation invites the inference that the force behind 
the barrier will have been building in pressure and its release will therefore result in a force of increased intensity. The available inference is made explicit in (17) and (18):

(17) Daily Mail, 28 December 2005

Asylum crisis as amnesty deal for 15,000 turns into stampede (headline)

(18) The Express, 22 May 2004

The ruling opens the floodgates for 666 asylum seekers to claim they have been treated inhumanely.

The schema in Figure 3f. constitutes the less prototypical concept of permission, onset letting of rest. Although more peripheral in most contexts, this schema is frequently invoked in anti-immigration discourse. Consider (19) and (20) by way of example:

(19) The Express, 9 December 2005

Any day now the Government will decide that, with the numbers of failed asylum seekers still here continuing to rise, the only way to solve the problem is to give yet another 'final' amnesty. This will enable [every one of them ${ }_{\mathrm{AGO}}$ ] to stay ...

(20) Sunday Mirror, 21 May 2006

A Crown Court judge has allowed [Ling Cheng, $34_{A G O}$ ], to stay in Britain indefinitely. Ling was ordered to leave the country by magistrates in Redhill, Surrey, eight months ago when they jailed him for selling pirate DVDs.

In these examples the verbs enable and allow again encode the role of a stronger Ant previously in place preventing the Ago in the object from realising its intrinsic force tendency but which disengages thereby allowing the Ago to manifest its 'natural' tendency. Indicated by stay in both (19) and (20), however, the Ago's intrinsic tendency is this time toward rest rather than motion. The stronger Ant is once again left implicit but can be taken as a previous legal 'force' which would have resulted in the Ago's removal but which has been suspended or superseded allowing the Ago to remain in Britain.

The schemas in Figure 3g. and 3h. counterpose those given as $3 \mathrm{f}$. and $3 \mathrm{e}$. respectively. In $3 \mathrm{~g}$. and $3 \mathrm{~h}$., a stronger Ant not previously in place comes into position against an Ago and thereby prevents it from realising its intrinsic force tendency. Thus, in both $3 \mathrm{f}$. and $3 \mathrm{~g}$. the Ago has an intrinsic tendency toward rest but in 3g. the Ago becomes blocked from realising this tendency whereas in $3 \mathrm{f}$. it is released and so able to manifest its intrinsic tendency. In 3e. and 3h. the Ago has an intrinsic force tendency toward motion which is blocked in $3 \mathrm{~h}$. but is allowed to manifest itself in $3 \mathrm{e}$. These two schemas (3g. and 3h.) operate over concepts of prevention rather than permission, then, and tend to be invoked in immigration discourse by statements concerning the deportation of immigrants or the prevention of entrance in the first place. In (21) and (22), for example, we see a stronger Ant coming into place causing the Ago with an intrinsic tendency toward rest to go from a stationary state to one of movement. The force-interactive construal in both examples is prompted by the verb remove which codes the role of an Ant as the stronger of two force entities and suggests resistance on the part of the Ago. ${ }^{16}$

(21) The Guardian, 13 August 2001

In the last financial year only 8,000 asylum seekers were removed, but [a change in resources ${ }_{\text {ANT }}$ is now feeding through, meaning [large numbers of asylum seekers ${ }_{\text {AGO }}$ ] will start to be removed by late autumn. 
(22) The Mirror, 19 April 2000

"[The policy ${ }_{\mathrm{ANT}}$ ] will allow [people who are refused ${ }_{\mathrm{AGO}}$ ] to be removed quickly from this country." (quoting Opposition Leader William Hague)

In (23) and (24), by contrast, we see a stronger Ant coming into place (through a tightening of security in (23) and a tightening of the law in (24)) to block the Ago, which is construed as having an intrinsic tendency toward motion, from continuing on its intended trajectory. The force-interactive construal and the role of the Ant as the stronger entity is marked by stop in (23) and prevent in (24).

(23) Daily Mail, 28 November 2003

(The Home Secretary) pointed to [tighter security at French ports ${ }_{\text {ANT }}$ ] which has stopped [6,300 illegal immigrants ${ }_{\mathrm{AGO}}$ ] from crossing the Channel so far this year.

(24) The Independent, 14 January 2000

It (the Home Office) says [the law ${ }_{\mathrm{ANT}}$ ] has been tightened to prevent [bogus asylum claims ${ }_{\mathrm{AGO}}$ ]

There is one final schema worth discussing in relation to the shift-in-state of opposition schema depicted in figure $3 \mathrm{~h}$. This is the 'secondary' steady-state schema modelled in figure 4.

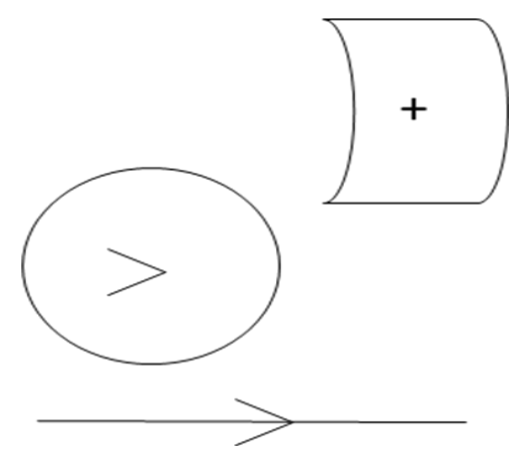

Figure 4. Secondary steady-state schema

From Figure 3 it is possible to characterise the concept of permission as involving the cessation of impingement and the concept of prevention as involving its implementation. The schema in Figure 4 represents the non-occurrence of impingement but its presupposed potential. That is, the schema in 4 presupposes the possibility for the event schematised in Figure $3 \mathrm{~h}$ resulting in the state of affairs schematised in Figure 2c. The pattern in Figure 4 is considered as 'secondary', then, because according to Talmy (2000: 421) it is conceptually derived from the negation of the schema in Figure 2c. A force-dynamic construal inherently involves an Ant and an Ago engaged in a force interaction. Any reference (implicit or explicit) to an Ant and Ago not so engaged depends on their potential to be so engagement (ibid.). And if the schema in Figure 4 presupposes those in the $3 \mathrm{~h}$. and $2 \mathrm{c}$., then it is also presupposed by the event schematised in 3e. The schema in 3e. represents 'onset' letting of motion. The schema in Figure 4, however, represents 'extended' letting of motion and is invoked in (25) and (26): 
(25) The Sun, 20 February 2004

BNP chief Mr Griffin later accused Mr Howard of playing the "typical Tory

con trick" by talking tough on asylum while still letting [immigrants ${ }_{\mathrm{AGO}}$ ] in.

(26) The Express, 30 August 2005

I find it absurd that, given the security fears since $9 / 11$, we are still letting [immigrants ${ }_{\mathrm{AGO}}$ ] into this country without interviewing them.

In both examples the force interaction is indicated by let and the extended nature of the force-dynamic relation is marked by adverbial particle still, which carries the implicature 'despite some compelling reason not to'.

\section{Concluding Remarks}

Hopefully, I have been able to demonstrate that and how force-interactive patterns feature in discourse on immigration to structure our conceptualisations of both physical and political/legal interactions in this domain. These schemas are invoked in discourse on immigration, then, and through repeated patterns of representation and processes of entrenchment can come to constitute, alongside other idealised cognitive models, the discourse of immigration (see Hart 2010). Force-interactive patterns are prompted by elements in text including certain adverbials, prepositions and various open-class elements which seem to have inherent in their conceptual representation a force-dynamic component.

The force-dynamic analyses we have presented reveal the ideological potential of force-dynamic conceptualisations in immigration discourse. The Cognitive Linguistic approach we have taken can therefore add to the armoury of CDA with force-dynamic indicators one further target on the analyst's hit list.

As will be clear from the analyses above, the force-dynamics system is in many respects similar to transitivity. For example, force-dynamics concerns the kind of process designated in the clause, i.e. whether or not a process is conceived as a force interaction, and in which interactional roles particular actors are cast. Force-dynamic conceptualisations therefore realise strategies of identification and framing, as well as positioning. As with transitivity, the force-dynamic system has the facility to analyse the same situation from one perspective or another and so is inherently ideological. However, the major contribution that the theory of force-dynamics can make is that it allows us to address the conceptual import of transitivity choices at the interpretation-stage, something which we have suggested is currently under-researched but fundamental to the claims of CDA.

\section{References}

Cap, P. (2006). Legitimization in political discourse. Newcastle: Cambridge Scholars Press.

Charteris-Black, J. (2004). Corpus approaches to critical metaphor analysis. Basingstoke: Palgrave Macmillan.

Charteris-Black, J. (2006). Britain as a container: Immigration metaphors in the 2005 election campaign. Discourse \& Society 17(6): 563-82.

Chilton, P. (2004). Analysing political discourse: Theory and practice. London: Routledge. 
Chilton, P. and C. Schäffner (1997). Discourse and politics. In T.A.van Dijk (ed.), Discourse as social interaction. London: Sage. pp. 206-30.

Croft, W. and D. A. Cruse (2004). Cognitive linguistics. Cambridge: Cambridge University Press.

Dervinyte, I. (2009). Conceptual emigration and immigration metaphors in the language of the press: A contrastive analysis. Studies about Languages 14: 49-55.

El Refaie, E. (2001). Metaphors we discriminate by: Naturalized themes in Austrian newspaper articles about asylum seekers. Journal of Sociolinguistics 5(3): 352-71.

Fairclough, N. (1995). Critical discourse analysis: The critical study of language. London: Longman.

Fauconnier, G. (1994). Mental spaces: Aspects of meaning construction in natural language. 2nd edition. Cambridge: Cambridge University Press.

Fauconnier, G. (2006). Cognitive linguistics. Encyclopedia of Cognitive Science. Oxford: Wiley.

Fillmore, C. (1982). Frame semantics. In Linguistics Society of Korea (eds.), Linguistics in the morning calm. Seoul: Hanshin Publishing Co. pp. 111-37.

Fowler, R. (1991). Language in the news: Discourse and ideology in the press. London: Routledge.

Fowler, R. (1996). On critical linguistics. In C. R. Caldas-Coulthard and M. Coulthard (eds.), Texts and practices. London: Routledge. pp. 3-14.

Fowler, R., R. Hodge, G. Kress and T. Trew (1979). Language and control. London: Routledge and Kegan Paul.

Gabrielatos, C. and P. Baker (2008). Fleeing, sneaking, flooding: A corpus analysis of discursive constructions of refugees and asylum seekers in the UK press 1996-2005. Journal of English Linguistics 36(1): 5-38.

Halliday, M. A. K. (1973). Explorations in the functions of language. London: Edward Arnold.

Hart, C. and D. Lukeš (eds.) (2007). Cognitive linguistics in critical discourse analysis: Application and theory. Newcastle: Cambridge Scholars Press.

Hart, C. (2010). Critical discourse analysis and cognitive science: New perspectives on immigration discourse. Basingstoke: Palgrave.

Hart, C. (ed.) (in press a). Critical discourse studies in context and cognition. Amsterdam: John Benjamins.

Hart, C. (in press b). Moving beyond metaphor in the Cognitive Linguistics Approach to CDA: Construal operations in immigration discourse. In C. Hart (ed.), Critical discourse studies in context and cognition. Amsterdam: John Benjamins.

Hodge, R. and G. Kress (1993). Language as ideology. 2nd edition. London: Routledge.

Johnson, M. (1987). The body in the mind: The bodily basis of meaning, imagination, and reason. Chicago: University of Chicago Press.

Kress, G. and R. Hodge (1979). Language as ideology. London: Routledge and Kegan Paul. 
Koller, V. (2004). Metaphor and gender in business media discourse: A critical cognitive study. Basingstoke: Palgrave.

Lakoff, G. and M. Johnson (1980). Metaphors we live by. Chicago: University of Chicago Press.

Langacker, R. W. (1987). Foundations of cognitive grammar, vol. I: Theoretical prerequisites. Stanford: Standford University Press.

Langacker, R. W. (1991). Foundations of cognitive grammar, vol. II: Descriptive application. Stanford: Stanford University Press.

Langacker, R. (2008). Cognitive grammar: A basic introduction. Oxford: Oxford University Press.

Levinson, S. C. (1983). Pragmatics. Cambridge: Cambridge University Press.

Musolff, A. (2004). Metaphor and political discourse: Analogical reasoning in debates about Europe. Basingstoke: Palgrave Macmillan.

O'Halloran, K. (2003). Critical discourse analysis and language cognition. Edinburgh: Edinburgh University Press.

Reisigl, M. and R. Wodak (2001). Discourse and discrimination: Rhetorics of racism and antiSemitism. London: Routledge.

Santa Ana, O. (2002). Brown tide rising: Metaphors of Latinos in contemporary American public discourse. Austin: University of Texas Press.

Talmy, L. (1988). Force dynamics in language and cognition. Cognitive Science 12: 49-100.

Talmy, L. (2000). Toward a cognitive semantics. Cambridge, MA.: MIT Press.

van Dijk, T. A. (1997b). Political discourse and racism: Describing others in western parliaments. In S. H. Riggins (eds.), The language and politics of exclusion: Others in discourse. Thousand Oaks, CA: Sage. pp. 31-64.

van Dijk, T. A. (2001b). Multidisciplinary CDA: A plea for diversity. In R. Wodak and M. Meyer (eds.), Methods of critical discourse analysis. London: Sage. pp. 95-120.

van Dijk, T. A. (2002). Ideology: Political discourse and cognition. In P. Chilton and C. Schäffner (eds.), Politics as text and talk: Analytic approaches to political discourse. Amsterdam: John Benjamins. pp. 203-38.

Widdowson, H. G. (2004). Text, context, pretext: Critical issues in discourse analysis. Oxford: Blackwell.

Wolf, H.-G. and F. Polzenhagen (2003). Conceptual metaphor as ideological stylistic means: An exemplary analysis. In R. Dirven, R. Frank and M. Putz (eds.), Cognitive models in language and thought: Ideology, metaphors and meanings. Berlin: Mouton de Gruyter. pp. 247-76. 
1 I make no claims to completeness here. There may of course be further force schemas which feature in immigration discourse. Similarly, my examples do not exhaust all of the occurrences of a particular force schema in the corpus from which they have been selected.

2 'Ideology' is understood throughout as a particular representation of reality or view of the world (Hodge and Kress 1993: 15).

3 Cognitive Linguistics emerged in the late 1970s in opposition to generative grammar and formal semantics.

4 This last claim, of course, is in line with Systemic Functional Linguistics in which Halliday (1973: 106) states that 'language lends structure to...experience and helps determine...way[s] of looking at things'.

5 Several alternative typologies of discursive strategies have also been proposed (e.g. Reisigl and Wodak 2001; Chilton and Schäffner 1997; Chilton 2004). Discursive strategies are intentional or institutionalised plans of linguistic practices for the reproduction of ideology whose adoption achieves ideological effects (Reisigl and Wodak 2001).

6 Deictic positioning can of course be social, spatial, or temporal (see Levinson 1983).

7 During this period, the European Union expanded twice and two UK General Elections were held. Largely fuelled by the media, the 2005 General Election was heavily focussed on the issue of immigration and extreme right-wing parties like the UK Independence Party and the British National Party gained significant ground.

8 See Croft and Cruse (2004: 45) for a more complete inventory of image schemas.

9 Since immigration is not necessarily construed as a force interaction, all of our examples can be said to instantiate a conceptual metaphor IMMIGRATION AS FORCE INTERACTION in the discourse of immigration. Many other conceptual metaphors constructed through discourse on immigration also contain a force-dynamic element. For example, those that construe immigration in terms of WAR or WATER (see Charteris-Black 2006; Dervinyté 2009; El Refaie 2001; Hart 2010; Santa Ana 2002). We may thus characterise these conceptual metaphors as more specific variants of the general scheme identified as IMMIGRATION AS FORCE INTERACTION which operates as a 'conceptual key' - a higher level metaphor that explains how several conceptual metaphors are related (Charteris-Black 2004: 16).

10 Talmy (2000: 417) in treats 'keep' as an honorary auxiliary.

11 These roles should not be confused with the standard participant role categories of Agent and Patient or Trajector and Landmark in Cognitive Grammar.

12 The Antagonist, as in (2), need not be explicitly referred to.

13 See Johnson (1987) for an alternative notation.

14 Note that diagrams such as those in Figure 2 should not be identified as image schemas per se but are intended only as representations of them (Langacker 2008: 32). The same schema with the same structural properties and entailments can be represented in alternative ways (cf. Johnson 1987).

15 Note that laterality is irrelevant in the force-dynamic system (Talmy 2000: 414) and that in either case the same image schema applies.

16 In this particular example notice that the dynamic nature of the Ant's oppositional state is marked explicitly by 'is now feeding through' and the onset nature of causation is marked by 'start to'. 